\title{
PROtocolized Care to Reduce HYpotension after Spinal Anesthesia (ProCRHYSA randomized trial): statistical plan
}

\author{
Samuele Ceruti ${ }^{*}$, Sergio De Vivo ${ }^{2}$, Mattia Peruzzo ${ }^{2}$, Denis De Bianchi ${ }^{2}$, Luciano Anselmi ${ }^{2}$, Andrea Saporito ${ }^{2}$ \\ From 10th WINFOCUS World Congress on Ultrasound in Emergency and Critical Care \\ Kuala Lumpur, Malaysia. 16-19 November 2014
}

\begin{abstract}
Background
Spinal anesthesia is a regional anesthesia technique widely employed in clinical practice. The common side effects consist in a reduction of systemic vascular resistances, with systemic hypotension. To prevent this complication, blind administration of fluids is commonly used. This is accomplished on an empirical basis, carrying risk of possible volume overload. Vena cava ultrasound has been shown to be an effective method to assess fluid responsiveness in critical care patients, however this method has never been studied in a non critical population. Aim of this study is to assess the efficacy of vena cava ultrasound guided titrated volume repletion in preventing spinal anesthesia induced hypotension in an elective surgical population.
\end{abstract}

\section{Objective}

To state our analysis plan for trial data.

\section{Methods}

We designed a randomized, case-control, prospective trial comparing standard practice to ultrasound guided vena cava fluid repletion before spinal anesthesia for elective surgery. After written informed consent, we randomized ASA 1 to 3 patients into two groups: the first received no preliminary volume repletion, according to standard local practice, while the second was assessed with vena cava echography before spinal anesthesia. Patients found to be responsive to fluids were given subsequent boluses of $500 \mathrm{ml}$ crystalloids before proceeding to spinal anesthesia and reassessed afterward until found

\footnotetext{
* Correspondence: samuele.ceruti@eoc.ch

'Department of Intensive Care Unit, Ospedale Regionale di Bellinzona, Via

Ospedale 12, 6500 Bellinzona, Switzerland

Full list of author information is available at the end of the article
}

euvolemic. Non invasive arterial pressure was periodically measured in any patient after spinal anesthesia until discharge to recovery room and the significant hypotension rate was subsequently calculated in the two groups.

Significant hypotension was defined according to international guidelines as fall in systolic arterial blood pressure more than $50 \mathrm{mmHg}$ or $25 \%$ from baseline value, an absolute value of systolic pressure less than $80 \mathrm{mmHg}$, an absolute value of mean pressure less than $60 \mathrm{mmHg}$, a reduction in mean arterial pressure more than $30 \%$ from baseline value and/or clinical symptoms of inadequate perfusion[i]. Exclusion criteria were considered contraindication to spinal anesthesia, patientâ $\epsilon^{\mathrm{TM}} \mathrm{S}$ refusal or lack of protocol adherence. Data are given as percentage of significant hypotension, $p$ value (p) and confidence intervals (CI). Power calculation was preliminary performed, identifying a sample size of 150 patients per group (95\% confidence level).

\section{Results}

A total of 64 patients were recruited in a 5 months period. 16 patients did not meet inclusion criteria and were excluded. 19 patients randomized to the cases group were subsequently excluded because of protocol adherence issues (poor echographic windows did not consent adequate vena cava diameter measurement). Post-spinal significant hypotension rate was $66 \%$ in control group $(\mathrm{N}=32)$ and $45 \%$ in the group whose preventive volume repletion was guided through vena cava ultrasound $(\mathrm{N}=32)$, this difference being statistically significant $(\mathrm{p}=0,043 \mathrm{CI}=95 \%)$.

\section{Conclusions}

Vena cava ultrasound assessment is an effective method to assess fluid responsiveness also in non critical patient who underwent preoperative fasting before elective 
surgery and can be routinely employed for guiding titrated and tailored preoperative volume repletion in order to reduce risk of significant hypotension after spinal anesthesia.

\section{Trial registration}

The trial is registered on http://www.clinicaltrials.gov with number NCT02070276.

\section{Authors' details}

'Department of Intensive Care Unit, Ospedale Regionale di Bellinzona, Via Ospedale 12, 6500 Bellinzona, Switzerland. ${ }^{2}$ Department of Anesthesiology, Ospedale Regionale di Bellinzona - Via Ospedale 12, 6500 Bellinzona, Switzerland.

Published: 9 March 2015

\section{References}

1. Carpenter RL, Caplan RA, Brown DL, Stephenson C, Wu R: Incidence and risk factors for side effects of spinal anesthesia. Anesthesiology 1992, 76(6):906-16.

2. Kim HJ, Kim JS: A cardiovascular collapse following vigorous cough during spinal anesthesia. Korean J Anesthesiol 2013, 65(6 Suppl):S49-50

3. Nogueira CS, Lima LC, Paris VC, Neiva PM, Otani ET, Couceiro Rde O, Burim F, Ferreira JA Jr, Cadecaro P: A comparative study between bupivacaine (S75-R25) and ropivacaine in spinal anesthesia for labor analgesia. Rev Bras Anestesiol 2010, 60(5):484-94.

4. Cherpanath TG, Geerts BF, Lagrand WK, Schultz MJ, Groeneveld AB: Basic concepts of fluid responsiveness. Neth Heart J 2013, 21(12):530-6.

5. Jabalameli M, Soltani HA, Hashemi J, Behdad S, Soleimani B: Prevention of post-spinal hypotension using crystalloid, colloid and ephedrine with three different combinations: A double blind randomized study. Adv Biomed Res 2012, 1:36, doi: 10.4103/2277-9175.100129. Epub 2012 Aug 28.

6. Xu S, Wu H, Zhao Q, Shen X, Guo X, Wang F: The median effective volume of crystalloid in preventing hypotension in patients undergoing cesarean delivery with spinal anesthesia. Rev Bras Anestesiol 2012, 62(3):312-24.

7. Buggy DJ, Power CK, Meeke R, O'Callaghan S, Moran C, O'Brien GT: Prevention of spinal anaesthesia-induced hypotension in the elderly: i.m. methoxamine or combined hetastarch and crystalloid. Br J Anaesth 1998, 80(2):199-203.

8. Pinsky MR, Payen D: Functional hemodynamic monitoring. Critical Care 2005, 9:566-572.

9. Vieillard-Baron A, Chergui K, Rabiller A, Peyrouset O, Page B, Beauchet A, Jardin F: Superior vena caval collapsibility as a gauge of volume status in ventilated septic patients. Intensive Care Med 2004, 30:1734-1739.

10. Zöllei E, Bertalan V, Németh A, Csábi P, László I, Kaszaki J, Rudas L: Noninvasive detection of hypovolemia or fluid responsiveness in spontaneously breathing subjects. BMC Anesthesiol 2013, 13(1):40.

11. Barbier $C$, Loubières $Y$, Schmit $C$, Hayon J, Ricôme JL, Jardin F, VieillardBaron A: Respiratory changes in inferior vena cava diameter are helpful in predicting fluid responsiveness in ventilated septic patients. Intensive Care Med 2004, 30(9):1740-6, Epub 2004 Mar 18.

12. Zhang Z, Xu X, Ye S, Xu L: Ultrasonographic Measurement of the Respiratory Variation in the Inferior Vena Cava Diameter Is Predictive of Fluid Responsiveness in Critically III Patients:Systematic Review and Meta-analysis. Ultrasound Med Biol 2014, pii:S0301-5629, (13)01237-4. [Epub ahead of print].

13. Lamia B, Ochagavia A, Monnet X, Chemla D, Richard C, Teboul JL: Echocardiographic prediction of volume responsiveness in critically ill patients with spontaneously breathing activity. . Intensive Care Med 2007, 33:1125-1132.

14. Muller L, Bobbia X, Toumi M, Louart G, Molinari N, Ragonnet B, Quintard H, Leone M, Zoric L, Lefrant JY, the AzuRea group: Respiratory variations of inferior vena cava diameter to predict fluid responsiveness in spontaneously breathing patients with acute circulatory failure: need for a cautious use. Crit Care 2012, 16(5):R188.
15. Monge García Ml, Gil Cano A, Gracia Romero M, Monterroso Pintado R, Pérez Madueño V, Díaz Monrové JC: Non-invasive assessment of fluid responsiveness by changes in partial endtidal $\mathrm{CO} 2$ pressure during a passive leg-raising maneuver. Ann Intensive Care 2012, 2:9.

16. Ceruti S, Peruzzo M, Kronemberg C, Anselmi L, Saporito A: Can non invasive methods for fluid responsive assessment optimize preventive volemic repletion in order to prevent significant hypotension after spinal anesthesia? A randomized trial. 0207, NCT0276 - http://www.clinicaltrial.gov.

17. SwissEthic: Commissions suisses d'éthique pour la recherche sur l'être humain.[http://www.swissethics.ch/index_f.html].

18. Schmidt GA, Kory P: Ultrasound-guided central venous catheter insertion: teaching and learning. Intensive Care Med 2014, 40(1):111-3, Epub 2013 Sep 7. PubMed.

doi:10.1186/2036-7902-7-S1-A3

Cite this article as: Ceruti et al:: PROtocolized Care to Reduce

HYpotension after Spinal Anesthesia (ProCRHYSA randomized trial): statistical plan. Critical Ultrasound Journal 2015 7(Suppl 1):A3.

\section{Submit your manuscript to a SpringerOpen ${ }^{\mathcal{O}}$ journal and benefit from:}

- Convenient online submission

- Rigorous peer review

- Immediate publication on acceptance

- Open access: articles freely available online

- High visibility within the field

- Retaining the copyright to your article

Submit your next manuscript at $>$ springeropen.com 